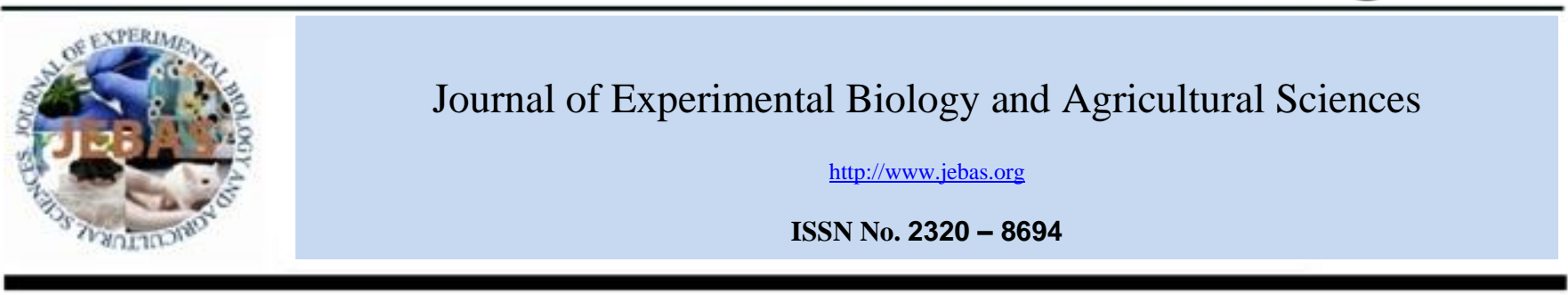

\title{
INTRASPECIFIC VARIATION AND MORPHOMETRIC ANALYSIS OF Juniperus phoenicea L. BRANCHES AND CONES FROM TUNISIA
}

\author{
Hanene Medini ${ }^{1, *}$, Mohamed Larbi Khouja ${ }^{2}$, Rachid Chemli ${ }^{1}$ and Fethia Harzallah-Skhiri ${ }^{3}$ \\ ${ }^{1}$ Laboratory of Pharmacognosy, Faculty of Pharmacy, University of Monastir, 5000 Monastir, Tunisia \\ ${ }^{2}$ National Institute for Research on Rural Engineering, Water and Forestry, Institution of Agricultural Research and Higher Education, BPNo. 2, 2080 Ariana, \\ Tunisia \\ ${ }^{3}$ Laboratory of Genetic, Biodiversity and Bio-Resources Valorization, Higher Institute of Biotechnology of Monastir, Avenue Tahar Haddad, University of \\ Monastir, 5000 Monastir, Tunisia
}

Received - May 25, 2016; Revision - July 04, 2016; Accepted - October 03, 2016

Available Online - October 07, 2016

DOI: http://dx.doi.org/10.18006/2016.4(5S).594.604

\section{KEYWORDS}

Juniperus phoenicea

Branches

Cones

Morphometry

Taxonomy

ABSTRACT

The intra- and inter populational geographic variation of eight distant populations of Juniperus phoenicea L. originating from Tunisia was examined biometrically on the basis of morphological-key characters of branches and cones. Seven and eight qualitative and quantitative (measured) traits of each branches and cones were studied on 45 and 29 vouchers, respectively. The principal component analysis (PCA) and hierarchical cluster analysis (HCA) of euclidean distances were performed to verify the hypothesis of geographic differentiation and for the existence of two J. phoenicea L. subspecies. The sampled populations differed significantly from one another, while the intra-populational variation was lower. Two major groups emerged on the PCA and HCA results, separating the continental populations from the coastal ones. Compared to the morphological traits of J. phoenicea subspecies in the literature and the basic flora, we confirm the existence of two J. phoenicea taxa: J. phoenicea ssp. turbinata was the reported from the coastal sites and J. phoenicea ssp. phoenicea located in the continental ones.
\end{abstract}

* Corresponding author

E-mail: hanene.medini@yahoo.fr (Hanene Medini)

Peer review under responsibility of Journal of Experimental Biology and Agricultural Sciences.

Production and Hosting by Horizon Publisher India [HPI] (http://www.horizonpublisherindia.in/).

All rights reserved.
All the article published by Journal of Experimental Biology and Agricultural Sciences is licensed under a Creative Commons Attribution-NonCommercial 4.0 International License Based on a work at www.jebas.org.

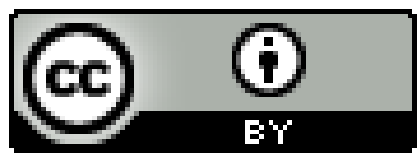




\section{Introduction}

Plants form a fundamental part of our life by providing us with breathable oxygen, food, fuel, medicine and more besides. Plants also help to regulate climate, provide habitats and food for insects and other animals and provide a natural way to regulate flooding. A good understanding of plants is necessary to improve agricultural productivity and sustainability, to discover new pharmaceuticals to plan for and mitigate the worst effects of climate changes, and to come to a better understanding of life (James et al., 2012).

With a growing human population and a changing climate, there is an increasing threat to many ecosystems. It is therefore becoming necessary to identify new or rare species and to measure their geographical extent as part of wider biodiversity projects. Preservation of isolated populations and defining the geographic range of species is widely demanded in conservation biology (Rojas, 1992; Sutherland, 2000; Scott et al., 2001). The traditional approach to identify species and their relation-ships is to train taxonomists who can examine specimens and assign taxonomic labels to them based on the morphometric characters (variables) of the species. Leaf and fruit morphology is central to plant taxonomy and systematics and it has mostly been studied using morphometrics characterization. Hence, studies on geographic variation in phenotype provide insight into the mechanism of evolution and have long contributed to a better understanding of diversification within and among species (Gould \& Jhonso, 1972; Thompson, 1994; Julietta et al., 2011). Thus, differentiation among populations of a species may be result of adaptative or non adaptative variations (Anderson \& Jhonson, 2008; Perez-Barrales et al., 2009). Some other factors such as divergent natural selection (Herrera et al., 2006) or isolation by distance (Gould \& Jhonso, 1972; Futuyma, 1998; Julieta et al., 2011) may also contributed in the species differentiation.

Juniperus phoenicea L. (Family Cupressaceae) is a monoecious or dioecious tree native to the coastal sites of the Mediterranean basin and extends to the mountains of western Arabia. It grows in various types in Mediterranean forests and sometimes forms pure stands (Quezel \& Barrero, 1980, Quezel \& Barrero, 1981; Quezel et al., 1992). Normally it gain the height of 6-8m but sometimes it grows like a shrub, with sally leaves and brown cones. It widely occurred in southern Europe, south-west Asia and northern Africa, but most frequently in the western part of the Mediterranean region (Quezel et al., 1992).

$J$. phoenicea L. belongs to the section Sabina of the genus Juniperus. It is a variable species characterized by a great morphological and biochemical differentiation, which was the reason for distinguishing three subspecies viz. J. phoenicea subsp. turbinata (Guss.); J. phoenicea subsp. Phoenicea; J. phoenicea subsp. mediterranea (Lebreton \& Thievend, 1981) (the most probably identical with subsp. turbinata).
Various studies were conducted on essential oil composition, phenolic composition and biological activities of $J$. phoenicea (Medini et al., 2013a; Medini et al., 2013b; Keskes et al., 2014), but till now no morphometric study was conducted on the leaves and cones of Tunisian J. phoenicea despite their large morphological variability. Previously, the biochemical polymorphism based on the essential oil chemical composition of $J$. phoenicea leaves collected from various localities in Tunisia was studied and existence of two clusters (the continental localities are clearly separated from the coastal ones) was deduced. That leads us to think for the hypothesis of the existence of two subspecies of Tunisian J. phoenicea (Medini et al., 2009; Medini et al., 2013a), contrarily to what was found in 'flora of Tunisia' by Pottier Alapetite \& Labbe (1954) which mentioned the existence of J. phoenicea L. without précising the subspecies. In the light of these findings we studied the biometric variability of $J$. phoenicea branches and cones.

\section{Materials and methods}

Morphological study was carried on the fresh samples of small twigs and cones of J. phoenicea (Schulz et al., 2003; Klimko et al., 2007; Guetet et al., 2009). Plant materials were collected in December 2011 from four coastal sites (Rimel, Laazib, Tabarka and Korbous) and four continental sites (Makther, Mallegue, J. Mansour and Dkhila) (Table 1). The samples were gathered separately from a variable number of individuals from every considered site. For each source, a voucher specimen was preserved in the laboratory of pharmacognosy in the Faculty of Pharmacy of Monastir.

\subsection{Twig related variables}

From each tree twigs (R1) with $30 \mathrm{~cm}$ in length and $1 \mathrm{~cm}$ in diameter were collected. For each branch twigs R2 was counted and it was followed by the observation and count of 5 twigs R2 and this was on which we repeated the same work. We counted the twigs R3 then the twigs R4 existing on R3.

Total five parameters were measured for morphometric study while two qualitative parameters related to the color and the twig aspect were considered for the data collection. The leaning twig is noted (1) and the adjusted one is noted (2). The light color of the twig is noted (3) and the darker one is noted (4) (Table 2).

\subsection{Cone related variables}

This study was carried out on 10 cones per tree gathered in every population. Then, eight parameters related to cone dimensions and quality were chosen, measured and characterized (Table 2). 
Table 1 Geographical coordinates of the collection sites of Juniperus phoenicea.

\begin{tabular}{|c|c|c|c|c|c|c|}
\hline \multirow[t]{2}{*}{ Sites } & \multirow[t]{2}{*}{ Code } & \multirow[t]{2}{*}{ Longitude (E) } & \multirow[t]{2}{*}{ Latitude (N) } & \multirow[t]{2}{*}{ Altitude (m) } & \multicolumn{2}{|c|}{ Number of individuals } \\
\hline & & & & & Branch morphology & Cone \\
\hline Mallegue (North-west) & (Mal) & $8^{\circ} 25^{\prime}$ & $36^{\circ} 18^{\prime}$ & 693 & 5 & 7 \\
\hline Laazib (coast) & $(\mathrm{La})$ & $9^{\circ} 51^{\prime}$ & $36^{\circ} 50^{\prime}$ & 45 & 5 & - \\
\hline Tabarka (North-west) & (Tab) & $8^{\circ} 45^{\prime}$ & $36^{\circ} 57^{\prime}$ & 22 & 4 & - \\
\hline Rimel (coast) & $(\mathrm{R})$ & $9^{\circ} 35^{\prime}$ & $37^{\circ} 14^{\prime}$ & 19 & 4 & 6 \\
\hline Korbous (coast) & $(\mathrm{Ko})$ & $10^{\circ} 35^{\prime}$ & $36^{\circ} 50^{\prime}$ & 180 & 8 & - \\
\hline Dkhila (North-west) & $(\mathrm{Dk})$ & $9^{\circ} 26^{\prime}$ & $36^{\circ} 11^{\prime}$ & 502 & 6 & - \\
\hline Makthar (North-west) & (Mak) & $9^{\circ} 17^{\prime}$ & $35^{\circ} 49^{\prime}$ & 785 & 8 & 6 \\
\hline J. Mansour (North-east) & $(\mathrm{JM})$ & $9^{\circ} 50^{\prime}$ & $36^{\circ} 15^{\prime}$ & 360 & 5 & 10 \\
\hline
\end{tabular}

Table 2 J. phoenicea twig and cone variables.

\begin{tabular}{|lll|}
\hline Organ & Code & Variables \\
\hline Branch (twig) & $\mathrm{NR}_{2} / \mathrm{R}_{1}$ & Number of branches (R2) on branch (R1) \\
& $\mathrm{LR}_{2}$ & Branch (R2) length \\
& $\mathrm{NR}_{3} / \mathrm{R}_{2}$ & Number of branch (R3) on branch (R2) \\
& $\mathrm{LR}_{3}$ & Branch (3) length \\
$\mathrm{NR}_{4} / \mathrm{R}_{3}$ & Number of branch (R4) on branch (R3) \\
$(1)$ & Leaning branch \\
& $(2)$ & Drawn branch \\
& $(3)$ & Branch color : light green \\
& $(4)$ & Branch : dark green \\
& $(5)$ & Smooth aspect of the cone \\
& $(6)$ & Rough aspect of the cone \\
& $\mathrm{H}$ & Cone height \\
& $\mathrm{Da}$ & Diameter 1 \\
& $\mathrm{Db}$ & Diameter 2 (perpendicular to diameter 2) \\
& $(7)$ & Proeminent tip \\
& $(8)$ & Not proeminent tip \\
& $\mathrm{NE}$ & Scales number \\
\hline Seeds & $\mathrm{NG}$ & Number of seeds per cone \\
\hline
\end{tabular}

\subsection{Data analysis}

Simple statistics (such as means and coefficient of variation) were used in order to compare variation between the studied populations. On each parameter a correlation analysis was used to estimate the relationship between the studied variables. The populations were clustered based on phenotypic treats. The general divergence among accessions was estimated using principal component analysis (PCA) and hierarchical cluster analysis (HCA). (All calculations were made using the SPS software (SPS 12.0) (SPSS Inc. Chicago, IL, USA).

\section{Results}

\subsection{Morphological variability of J. phoenicea twigs}

The analysis of the morphometric traits revealed that among seven J. phoenicea studied populations, four of them showed a highly significant variation with a large phenotypic heterogeneity (Table 3). Generally, correlations between various features were statistically insignificant except some significant correlations including the length of branches R2 (LR2) which is positively correlated with the number of branches R3 (NR3) (0.5), the qualitative character 'color of branches' noted $(4) /(5)$ is positively correlated with the character (1)/(2) (leaning branch/drawn branch) (1.0) and negatively correlated with the character "number of branches R4 on branches R3 (NR4/NR3). Both qualitative characters (color of branches and leaning branch/drawn branch) are negatively correlated (-0.5) (Table 4).

In order to determine and verify the variations between populations and individuals, data were analyzed by principal component analysis (PCA) and Hierarchical cluster analysis (HCA). A graphic representation of the variable projection onto the first principal components is given in figure 1 . The horizontal axis explained $38.5 \%$ of the total variance while the vertical axis a further $21.61 \%$, generating two major groups. 
Table 3 Mean \pm SD Results for seven descriptors of J. phoenicea twigs.

\begin{tabular}{|c|c|c|c|c|c|c|c|c|}
\hline Site & Specimens code & NR2 & LR2 (mm) & NR3 & LR3 (mm) & NR4/R3 & $(1) /(2)$ & $(4) /(5)$ \\
\hline \multirow[t]{5}{*}{ J.Mansour } & JM1 & $11 \pm 0.07$ & $13.2 \pm 5.52$ & 13.0 .00 & $4.2 \pm 0.89$ & $34.5 \pm 1.5$ & $1 \pm 0.00$ & $4 \pm 0.00$ \\
\hline & JM2 & $14 \pm 0.50$ & $9.2 \pm 1.22$ & $5.7 \pm 1.80$ & $4.2 \pm 1.21$ & $23.6 \pm 2.3$ & $1 \pm 0.00$ & $4 \pm 0.00$ \\
\hline & JM3 & $11 \pm 1.01$ & $12.8 \pm 2.01$ & $10.6 \pm 2.56$ & $4.7 \pm 0.94$ & $33.5 \pm 2.53$ & $1 \pm 0.00$ & $4 \pm 0.00$ \\
\hline & JM4 & $9 \pm 0.4$ & $12.6 \pm 1.92$ & $8.3 \pm 0.83$ & $3.9 \pm 0.59$ & $27.7 \pm 1.45$ & $1 \pm 0.00$ & $4 \pm 0.00$ \\
\hline & JM5 & $9 \pm 0.00$ & $10.7 \pm 0.83$ & $11.4 \pm 1.46$ & $4.2 \pm 0.59$ & $33.0 \pm 4.89$ & $1 \pm 0.00$ & $4 \pm 0.00$ \\
\hline \multirow[t]{5}{*}{ Mallegue } & Mal1 & $16 \pm 1,54$ & $13.9 \pm 2$ & $22.7 \pm 3.18$ & $3.0 \pm 0.74$ & $17.3 \pm 3.21$ & $1 \pm 0.00$ & $4 \pm 0.00$ \\
\hline & Mal2 & $14 \pm 1.32$ & $14.4 \pm 3.09$ & $27.3 \pm 4.31$ & $2.9 \pm 0.63$ & $18.8 \pm 3.45$ & $1 \pm 0.00$ & $4 \pm 0.00$ \\
\hline & Mal3 & $14 \pm 1.47$ & $12.2 \pm 2.92$ & $18.2 \pm 4.88$ & $4.3 \pm 0.75$ & $32.8 \pm 1.41$ & $1 \pm 0.00$ & $4 \pm 0.00$ \\
\hline & Mal4 & $13 \pm 2.03$ & $13.6 \pm 0.80$ & $13.9 \pm 1.01$ & $3.6 \pm 0.82$ & $23.4 \pm 0.89$ & $1 \pm 0.00$ & $4 \pm 0.00$ \\
\hline & Mal5 & $15 \pm 2.90$ & $12.8 \pm 1.2$ & $11.4 \pm 1.14$ & $3.5 \pm 1.19$ & $20.1 \pm 1.78$ & $1 \pm 0.00$ & $4 \pm 0.00$ \\
\hline \multirow[t]{5}{*}{ Laazib } & La1 & $18 \pm 1.78$ & $14.4 \pm 4.83$ & $27.5 \pm 8.90$ & $4.5 \pm 0.88$ & $6.9 \pm 3.45$ & $2 \pm 0.00$ & $5 \pm 0.00$ \\
\hline & La2 & $13 \pm 0.38$ & $15.0 \pm 2.29$ & $26.5 \pm 2.97$ & $4.0 \pm 0.68$ & $6.5 \pm 4.07$ & $2 \pm 0.00$ & $5 \pm 0.00$ \\
\hline & $\mathbf{L a 3}$ & $13 \pm 0.00$ & $15.3 \pm 3.91$ & $26.3 \pm 2.24$ & $4.3 \pm 0.87$ & $7.7 \pm 2.45$ & $2 \pm 0.00$ & $5 \pm 0.00$ \\
\hline & La4 & $11 \pm 3.29$ & $19.4 \pm 3.51$ & $26.0 \pm 8.16$ & $4.7 \pm 0.71$ & $7.7 \pm 2.32$ & $2 \pm 0.00$ & $5 \pm 0.00$ \\
\hline & La5 & $17 \pm 0.67$ & $15.3 \pm 3.85$ & $22.0 \pm 3.79$ & $4.1 \pm 1.12$ & $10.4 \pm 1.89$ & $2 \pm 0.00$ & $5 \pm 0.00$ \\
\hline \multirow[t]{4}{*}{ Tabarka } & Tab1 & $17 \pm 1.74$ & $12.4 \pm 1.31$ & $16.0 \pm 0.73$ & $3.5 \pm 0.54$ & $9.6 \pm 4.02$ & $1 \pm 0.00$ & $4 \pm 0.00$ \\
\hline & Tab2 & $12 \pm 1.99$ & $13.8 \pm 2.74$ & $15.8 \pm 4.16$ & $3.6 \pm 0.68$ & $8.7 \pm 1.87$ & $1 \pm 0.00$ & $4 \pm 0.00$ \\
\hline & Tab3 & $14 \pm 2.09$ & $11.9 \pm 0.79$ & $16.3 \pm 1.84$ & $3.5 \pm 0.48$ & $9.2 \pm 2.93$ & $1 \pm 0.00$ & $4 \pm 0.00$ \\
\hline & Tab4 & $17 \pm 1.63$ & $13.2 \pm 1.48$ & $16.0 \pm 1.93$ & $3.5 \pm 0.60$ & $9.4 \pm 2.35$ & $1 \pm 0.00$ & $4 \pm 0.00$ \\
\hline \multirow[t]{8}{*}{ Makthar } & Mak1 & $19 \pm 0.07$ & $14.6 \pm 5.14$ & $22.8 \pm 1.53$ & $3.2 \pm 0.43$ & $16.6 \pm 4.7$ & $1 \pm 0.00$ & $4 \pm 0.00$ \\
\hline & Mak2 & $21 \pm 0.00$ & $14.7 \pm 4.72$ & $22.5 \pm 2.97$ & $3.3 \pm 0.40$ & $20.6 \pm 1.23$ & $1 \pm 0.00$ & $4 \pm 0.00$ \\
\hline & Mak3 & $23 \pm 0.98$ & $11.4 \pm 1.05$ & $19.5 \pm 4.03$ & $3.5 \pm 0.66$ & $20.4 \pm 5.01$ & $1 \pm 0.00$ & $4 \pm 0.00$ \\
\hline & Mak4 & $20 \pm 0.56$ & $14.0 \pm 0.84$ & $19.5 \pm 4.87$ & $3.8 \pm 0.48$ & $24.0 \pm 3.65$ & $1 \pm 0.00$ & $4 \pm 0.00$ \\
\hline & Mak5 & $16 \pm 1.07$ & $13.4 \pm 2.32$ & $24.0 \pm 1.63$ & $3.5 \pm 0.57$ & $18.4 \pm 4.52$ & $1 \pm 0.00$ & $4 \pm 0.00$ \\
\hline & Mak6 & $22 \pm 1,59$ & $11.7 \pm 0.99$ & $18.3 \pm 2.24$ & $3.1 \pm 0.55$ & $15.9 \pm 1.78$ & $1 \pm 0.00$ & $4 \pm 0.00$ \\
\hline & Mak7 & $18 \pm 1.45$ & $12.8 \pm 0.56$ & $14.0 \pm 1.26$ & $3.2 \pm 0.55$ & $20.1 \pm 1.36$ & $1 \pm 0.00$ & $4 \pm 0.00$ \\
\hline & Mak8 & $14 \pm 1.39$ & $12.8 \pm 1.00$ & $15.8 \pm 2.35$ & $3.3 \pm 0.52$ & $16.3 \pm 2.56$ & $1 \pm 0.00$ & $4 \pm 0.00$ \\
\hline \multirow[t]{7}{*}{ Dkhila } & Dk1 & $15 \pm 0.45$ & $12.9 \pm 1.04$ & $14.3 \pm 0.86$ & $3.1 \pm 0.68$ & $15.4 \pm 1.23$ & $1 \pm 0.00$ & $4 \pm 0.00$ \\
\hline & Dk2 & $12 \pm 2.54$ & $13.9 \pm 1.33$ & $15.0 \pm 3.18$ & $3.9 \pm 0.97$ & $29.8 \pm 4.78$ & $1 \pm 0.00$ & $4 \pm 0.00$ \\
\hline & Dk3 & $16 \pm 2.67$ & $12.6 \pm 1.09$ & $17.3 \pm 5.29$ & $3.4 \pm 0.43$ & $21.4 \pm 3.59$ & $1 \pm 0.00$ & $4 \pm 0.00$ \\
\hline & Dk4 & $15 \pm 3.09$ & $12.4 \pm 3.08$ & $15.0 \pm 2.83$ & $3.4 \pm 0.65$ & $23.8 \pm 2.86$ & $1 \pm 0.00$ & $4 \pm 0.00$ \\
\hline & Dk5 & $11 \pm 3.76$ & $12.2 \pm 1.12$ & $13.8 \pm 2.35$ & $3.4 \pm 0.69$ & $30.6 \pm 0.48$ & $1 \pm 0.00$ & $4 \pm 0.00$ \\
\hline & Dk6 & $13 \pm 2.40$ & $13.7 \pm 0.97$ & $14.8 \pm 2.77$ & $3.4 \pm 0.60$ & $31.8 \pm 0.95$ & $1 \pm 0.00$ & $4 \pm 0.00$ \\
\hline & R1 & $13 \pm 3.02$ & $16.8 \pm 1.46$ & $19.3 \pm 2.11$ & $3.6 \pm 0.47$ & $10.3 \pm 1.02$ & $2 \pm 0.00$ & $5 \pm 0.00$ \\
\hline \multirow[t]{5}{*}{ Rimel } & $\mathbf{R 2}$ & $10 \pm 1.65$ & $18.2 \pm 3.30$ & $14.0 \pm 1.63$ & $4.2 \pm 0.97$ & $9.3 \pm 3.05$ & $2 \pm 0.00$ & $5 \pm 0.00$ \\
\hline & $\mathbf{R 3}$ & $12 \pm 0.00$ & $14.2 \pm 3.54$ & $15.3 \pm 2.57$ & $4.0 \pm 0.67$ & $8.4 \pm 3.59$ & $2 \pm 0.00$ & $5 \pm 0.00$ \\
\hline & R4 & $12 \pm 0.53$ & $16.9 \pm 1.96$ & $20.8 \pm 4.09$ & $4.6 \pm 0.89$ & $5.7 \pm 2.58$ & $2 \pm 0.00$ & $5 \pm 0.00$ \\
\hline & Ko1 & $12 \pm 0.53$ & $14.1 \pm 2.15$ & $13.2 \pm 1.57$ & $3.6 \pm 0.60$ & $6.3 \pm 2.73$ & $2 \pm 0.00$ & $5 \pm 0.00$ \\
\hline & Ko2 & $15 \pm 2.89$ & $13.2 \pm 1.94$ & $12.8 \pm 1.69$ & $4.0 \pm 0.34$ & $7.8 \pm 3.59$ & $2 \pm 0.00$ & $5 \pm 0.00$ \\
\hline \multirow[t]{6}{*}{ Korbous } & Ko3 & $18 \pm 1.39$ & $13.5 \pm 3.72$ & $10.0 \pm 1.26$ & $4.1 \pm 1.06$ & $6.6 \pm 0.79$ & $2 \pm 0.00$ & $5 \pm 0.00$ \\
\hline & Ko4 & $19 \pm 2.05$ & $15.5 \pm 2.07$ & $15.0 \pm 2.63$ & $4.5 \pm 1.10$ & $8.0 \pm 1.37$ & $2 \pm 0.00$ & $5 \pm 0.00$ \\
\hline & Ko5 & $16 \pm 0.78$ & $11.1 \pm 3.92$ & $11.5 \pm 3.06$ & $4.0 \pm 0.98$ & $6.4 \pm 1.98$ & $2 \pm 0.00$ & $5 \pm 0.00$ \\
\hline & Ko6 & $16 \pm 0.00$ & $15.1 \pm 2.51$ & $12.3 \pm 2.46$ & $3.7 \pm 0.64$ & $6.8 \pm 2.07$ & $2 \pm 0.00$ & $5 \pm 0.00$ \\
\hline & Ko7 & $16 \pm 0.34$ & $15.1 \pm 1.31$ & $16.5 \pm 1.55$ & $4.1 \pm 0.94$ & $7.7 \pm 4.03$ & $2 \pm 0.00$ & $5 \pm 0.00$ \\
\hline & Ko8 & $16 \pm 0.00$ & $14.0 \pm 0.81$ & $13.0 \pm 1.26$ & $4.2 \pm 0.46$ & $8.2 \pm 3.08$ & $2 \pm 0.00$ & $5 \pm 0.00$ \\
\hline
\end{tabular}

NR2 : Number of branches (R2) on Branch (R1), LR2 : Branch (R2) length, NR3 : Number of branches (R3) on branch (R2), LR3 : Branch (R3) length, NR4 : Number of branches (R4) on branch (R3), (1) leaning branch/ (2) Drawn branch, (4) light green branch/ (5) Dark green branch. 


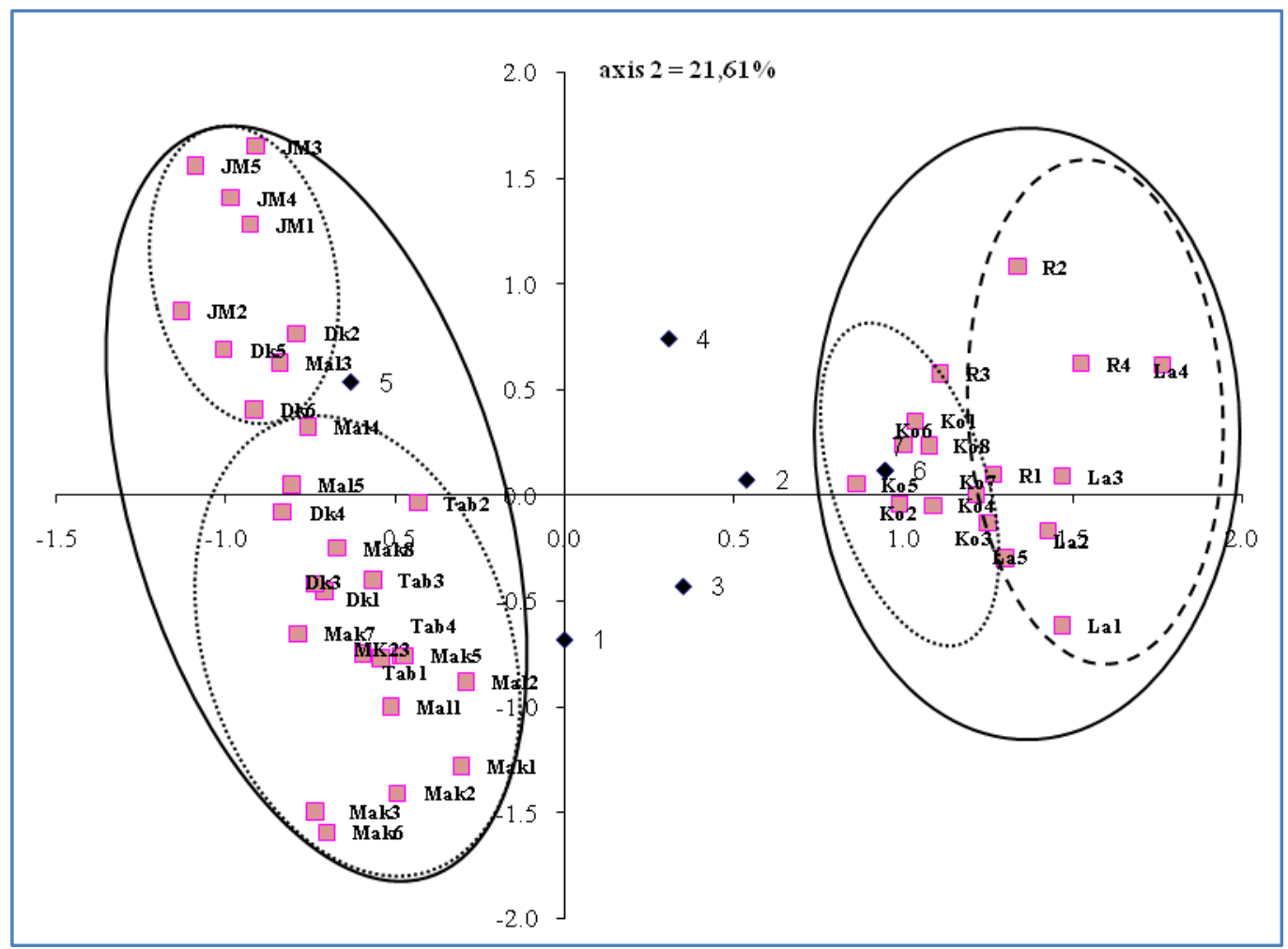

Figure 1 Principal component analysis (PCA) of the twig morphometric variables of $45 \mathrm{~J}$. phoenicea individuals [La : laazib, Ko, Korbous, R : Rimel, JM : J. Mansour, Dk : Dkhila, Tab : Tabarka, Mal : Mallegue, Dk : Dkhila, Jpp : J. phoenicea ssp . phoenicea, Jpt : J. phoenicea ssp. Turbinate]

Specimens from the populations of Makther, Dkhila, Mallegue and Tabarka generated a distinct group (G1) which is negatively correlated with the first axis. These populations are characterized by a similar morohological qualitative features (leaning character and light color of branches) and relatively low values of the branch lengths (LR2). Two subgroups were distinguished as Subgroup G1a: represented by the population of Makther (8 individuals), 4 individuals from the population of Tabarka, 4 individuals from Mallegue and 3 individuals from Dkhila. Specimens are characterized by a relatively high average of the parameter 'number of branchs R2 $(15<\mathrm{NR} 2<$ $22)$ and the length of branches R3 $(12.2 \mathrm{~mm}<\mathrm{LR} 3<14.7 \mathrm{~mm})$. While subgroup G1b included one specimen from Mallegue and 3 specimens from Dkhila. They presented a relatively low averages of the parameter number of branches R2 $(11<\mathrm{NR} 2<$ 14) and the branch length R2 $(9.2 \mathrm{~mm}<\mathrm{LR} 2<13.7 \mathrm{~mm})$, a relatively high values of the character length of branches R3 $(3.4 \mathrm{~mm}<\mathrm{LR} 3<4.7 \mathrm{~mm})$ and the number of branches R4 $(29.8$ $<\mathrm{NR} 4<34.5 \mathrm{~mm})$.

The second group G2 is positively correlated with the first axis. It is formed by the populations of Rimel, Laazib and
Korbous. They presented the same qualitative morphological characters (drawn and dark branches). Also, theses specimens presented the highest levels of the branch lengths R2 $(11.1 \mathrm{~mm}$ $<\mathrm{LR} 2<14.7 \mathrm{~mm})$ and R3 $(3.6 \mathrm{~mm}<\mathrm{LR} 3<4.7 \mathrm{~mm})$. However, they are characterized by a relatively low mean values of the parameter number of branches R4 $(6.6<\mathrm{NR} 4<10.3)$.

The second group is also divided into two subgroups. The first one consists of 10 specimens from Korbous, one specimen from Rimel and one specimen from Laazib. They are characterized by the highest branch number (R2) mean (12 < NR2 < 18) and the lowest branch number (R3) mean $(10<\mathrm{NR} 3$ $<15.3)$ except the specimen of Laazib which presented a relatively high mean of the same character $(\mathrm{NR} 3=22)$.

The second subgroup is formed by four specimens from Laazib and three specimens from Rimel. They presented the highest values of the character branch length (R2) $(14.2 \mathrm{~mm}<\mathrm{LR} 2<$ $19.4 \mathrm{~mm})$ and branch number (R3) $(14<\mathrm{NR} 3<27.5)$. The results of PCA are in agreement with what is found in HCA analysis (Figure 2). 


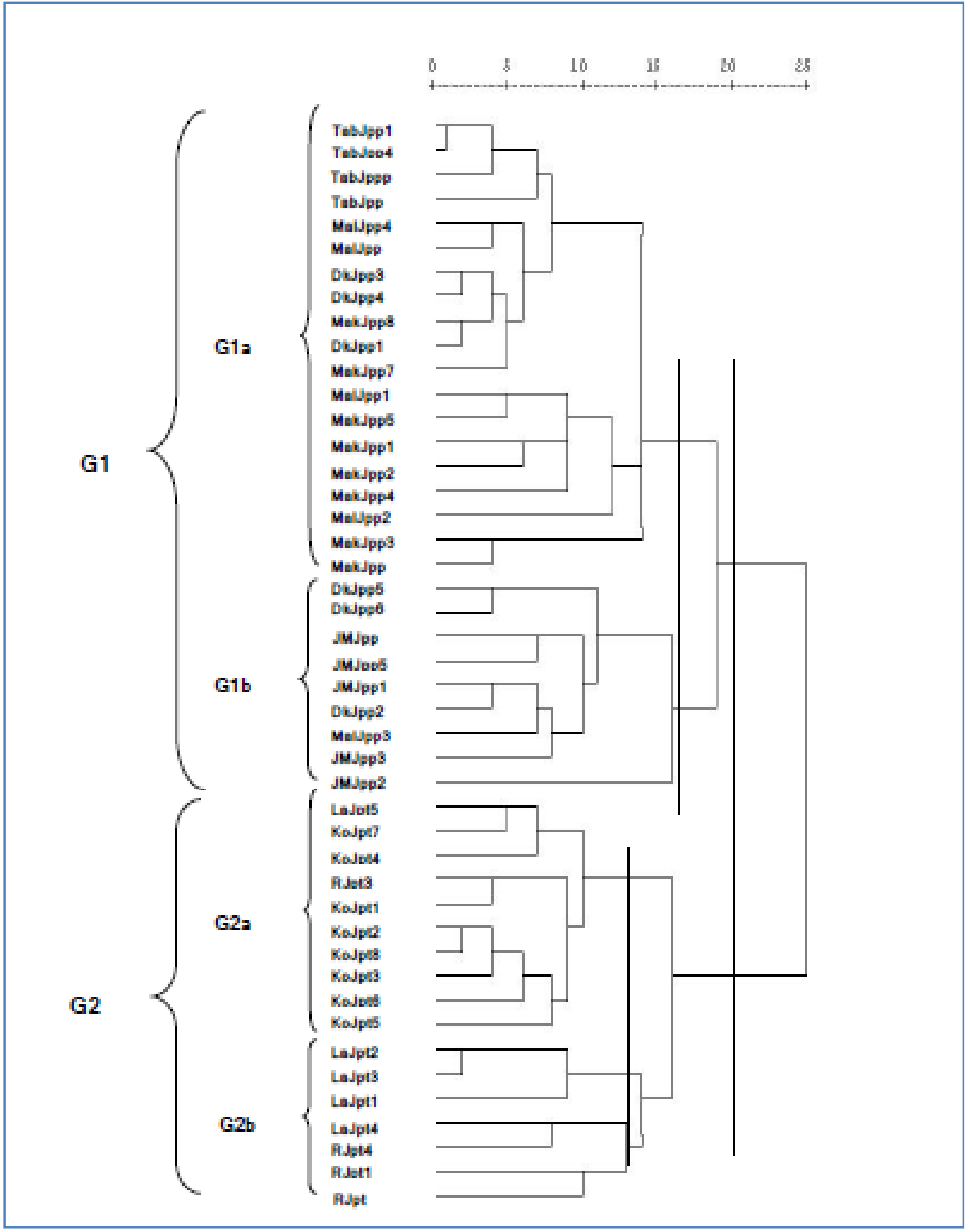

Figure 2 Dendrogram obtained by hierarchical cluster analysis (HCA) based on the Euclidean distances between twig morphometric variables of 45 J. phoenicea individuals. [La : laazib, Ko, Korbous, R : Rimel, JM : J. Mansour, Dk : Dkhila, Tab : Tabarka, Mal : Mallegue, Dk : Dkhila, Jpp : J. phoenicea ssp . phoenicea, Jpt : J. phoenicea ssp. Turbinata] 


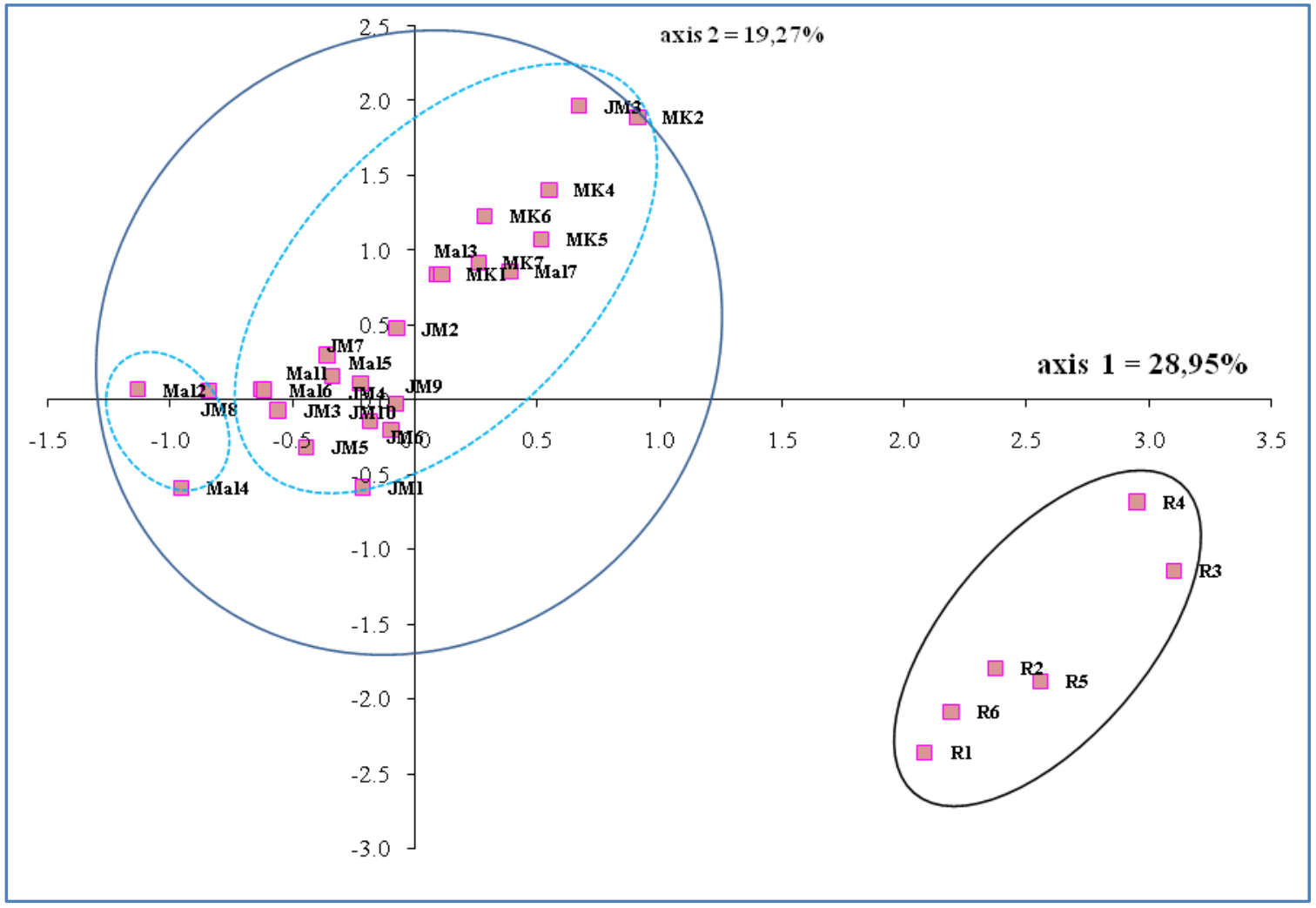

Figure 3 Principal component analysis (PCA) of the cone morphometric variables of 29 individuals de J. phoenicea individuals.

\subsection{Morphological variability of J. phoenicea cones}

Similarly to twigs variability, cone variables also vary from one individual to another. The correlation between six parameters from eight studied is statistically significant at a level ( $p$ < 0.05) which leads us to conclude the existence of a large phenotypic heterogeneity between populations. Specimens of Makther population showed the highest averages of the feature 'number of cones per branch' $(16<\mathrm{NC}<22)$ followed by J. Mansour, then Mallegue and Rimel. Specimens collected from Mallegue are distinguished by the highest level of the cone diameter $(8.5<\mathrm{D}<11.5)$, followed by specimens collected from Makther. On the other hand, specimens collected from J. Mansour presents relatively lowest means of the cone height $(8.9 \mathrm{~mm}<\mathrm{H}<9.9 \mathrm{~mm})$ (Table 5$)$.

However, it is possible to define many homogeneous classes presenting overlaps between each other, for the parameters $\mathrm{NC}, \mathrm{NE}, \mathrm{NG}, \mathrm{H}$ and diameter for all specimens. Some characters in one population are strongly correlated. While, within other populations the correlations are slight and insignificant. It indicates that differentiation of specimens is heterogeneous within each sampled population. However, the qualitative parameter (appearance of the cone: smooth or rough cone $(5) /(6))$ is inversely correlated to the parameter 'aspect of the tip' (proeminent tip/ not proeminent tip $(7) /(8))(-0.85)$. The most correlated features are cones height $(\mathrm{H})$ and cone diameter (D) (0.6) (Table 6).

A graphical representation by using principal component analysis (PCA) of the projection of different variables and specimens values on to the first principal components is given in figure 3 . The horizontal axis (axis 1) represents $28.95 \%$ of the total variations and it is positively loaded with the various parameters such as cone number per branch (NC), scales number per cone (NE), seeds number (NG) and the cone diameter (Da). It is negatively correlated by only one character 'cone aspect' (smooth or rough cone (5)/(6)). The second axis absorbs $19.7 \%$ of the total inertia. It is defined positively by the parameter 'cone height' $(H)$ and negatively correlated with the parameter cone diameter (Da).

The scores and loading plots in the principal component axis 1 and axis 2 spaces (PCA) (Figure 3), and the hierarchical cluster analysis (HCA) (Fig.4) showed two groups. The first group is composed by specimens from the majority of populations (Makther, Mallegue and J. Mansour). It is characterized by similar qualitative parameters: rough appearance cone with a prominent tip. 


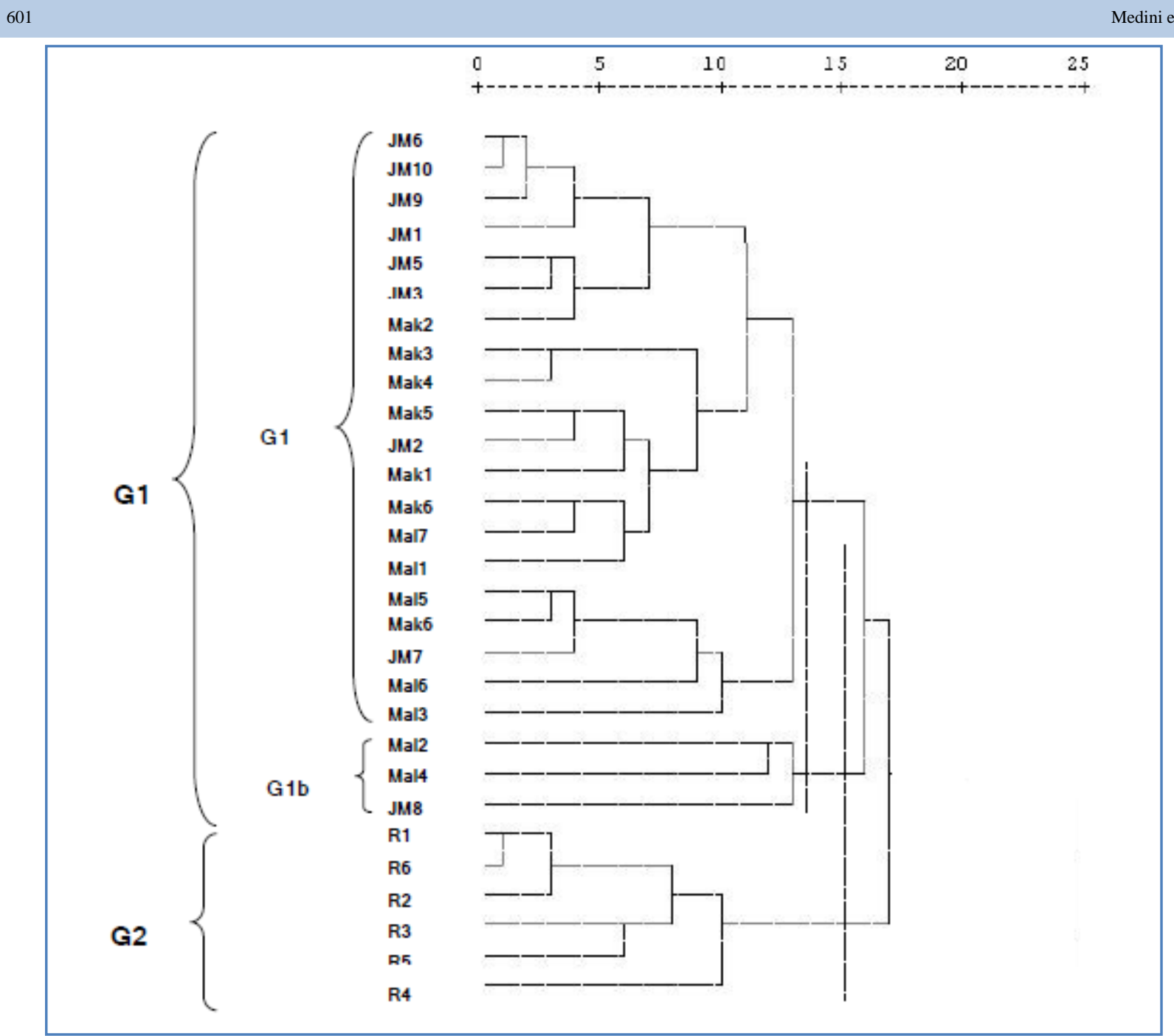

Figure 4 Dendrogram obtained by hierarchical cluster analysis (HCA) based on the Euclidean distances between cone morphometric variables of $29 \mathrm{~J}$. phoenicea individuals.

This group is divided into two subgroups, the first subgroup (G1a) being composed by Makther specimens, seven specimens from J. Mansour and four specimens from Mallegue. It is characterized by the most important seeds number $(4<\mathrm{NG}<6)$ and the highest diameter values $(8.2 \mathrm{~mm}$ $<\mathrm{D}<10.8 \mathrm{~mm})$. One specimen collected from Makther and two specimens collected from Mallegue formed the second subgroup (G1b). These specimens are characterized by the lowest levels of the seeds number $(35<\mathrm{NG}<4)$ and cone diameter $(6.9 \mathrm{~mm}<\mathrm{D}<9 \mathrm{~mm})$. However, the population of Rimel stands out clearly, forming a separate group in PCA (Fig.3) and a deep dichotomy in cluster analysis (Figure 4).

Table 4 Correlations coefficients between \& considered characters of $J$. phoenicea twigs from all populations sampled.

\begin{tabular}{|c|c|c|c|c|c|c|c|}
\hline & NR2 & LR2 & NR3 & LR3 & NR4 & $(1) /(2)$ & $(4) /(5)$ \\
\hline NR2 & 1.0 & & & & & & \\
\hline LR2 & -0.1 & 1.0 & & & & & \\
\hline NR3 & 0.2 & 0.5 & 1.0 & & & & \\
\hline LR3 & -0.2 & 0.2 & 0.0 & 1.0 & & & \\
\hline NR4 & -0.2 & -0.1 & -0.2 & 0.3 & 1.0 & & \\
\hline$(1) /(2)$ & -0.1 & 0.3 & 0.1 & 0.3 & -0.5 & 1.0 & \\
\hline$(4) /(5)$ & -0.1 & 0.3 & 0.1 & 0.3 & -0.5 & 1.0 & 1.0 \\
\hline
\end{tabular}


Table 5 Results of evaluated eight descriptors of J. phoenicea cones (Mean \pm SD)

\begin{tabular}{|c|c|c|c|c|c|c|c|c|c|}
\hline Sites & Specimens & $\mathrm{NC}$ & $(5) /(6)$ & NE & NG & $\mathbf{H}(\mathbf{m m})$ & Da (mm) & $\mathrm{Db}(\mathrm{mm})$ & (7) / (8) \\
\hline \multirow[t]{10}{*}{ J. Mansour } & JM1 & $11 \pm 3.5$ & $6 \pm 0.00$ & $6 \pm 0.0$ & $5 \pm 0.0$ & $9.2 \pm 0.1$ & $8.6 \pm 0.1$ & $8.6 \pm 1.2$ & $7 \pm \pm 0.0$ \\
\hline & JM2 & $17 \pm 0.9$ & $6 \pm 0.00$ & $6 \pm 0.0$ & $5 \pm 0.0$ & $9.6 \pm 0.8$ & $9.4 \pm 0.5$ & $9.6 \pm 1.7$ & $7 \pm \pm 0.0$ \\
\hline & JM3 & $17 \pm 1.3$ & $6 \pm 0.00$ & $6 \pm 0.0$ & $4 \pm 0.3$ & $9.2 \pm 1.2$ & $8.7 \pm 1.2$ & $9.0 \pm 2.3$ & $7 \pm \pm 0.0$ \\
\hline & JM4 & $14 \pm 1.7$ & $6 \pm 0.00$ & $6 \pm 0.0$ & $4 \pm 0.1$ & $96 \pm 0.3$ & $9.3 \pm 0.8$ & $8.2 \pm 2.5$ & $7 \pm \pm 0.0$ \\
\hline & JM5 & $11 \pm 2.8$ & $6 \pm 0.00$ & $6 \pm 0.0$ & $4 \pm 0.0$ & $9.6 \pm 1.0$ & $8.6 \pm 1.9$ & $8.9 \pm 1.6$ & $7 \pm \pm 0.0$ \\
\hline & JM6 & $8 \pm 3.1$ & $6 \pm 0.00$ & $6 \pm 0.0$ & $5 \pm 0.1$ & $9.6 \pm 1.5$ & $9.1 \pm 1.1$ & $9.4 \pm 0.9$ & $7 \pm \pm 0.0$ \\
\hline & JM7 & $17 \pm 0.4$ & $6 \pm 0.00$ & $7 \pm 0.4$ & $5 \pm 0.0$ & $9.9 \pm 1.6$ & $8.4 \pm 0.5$ & $9.6 \pm 0.8$ & $7 \pm \pm 0.0$ \\
\hline & JM8 & $25 \pm 3.6$ & $6 \pm 0.00$ & $6 \pm 0.0$ & $4 \pm 0.3$ & $8.9 \pm 0.9$ & $8.2 \pm 2.5$ & $9.0 \pm 1.1$ & $7 \pm \pm 0.0$ \\
\hline & JM9 & $9 \pm 2.9$ & $6 \pm 0.00$ & $6 \pm 0.0$ & $5 \pm 0.0$ & $9.9 \pm 0.9$ & $9.0 \pm 1.4$ & $8.4 \pm 2.0$ & $7 \pm \pm 0.0$ \\
\hline & JM10 & $9 \pm 2.6$ & $6 \pm 0.00$ & $6 \pm 0.0$ & $5 \pm 0.0$ & $9.6 \pm 1.3$ & $9.2 \pm 0.4$ & $8.3 \pm 1.7$ & $7 \pm \pm 0.0$ \\
\hline \multirow[t]{7}{*}{ Mallegue } & Mal1 & $16 \pm 1.9$ & $6 \pm 0.00$ & $7 \pm 0.0$ & $5 \pm 0.0$ & $9.3 \pm 1.9$ & $8.5 \pm 1.2$ & $8.4 \pm 0.6$ & $7 \pm \pm 0.0$ \\
\hline & Mal2 & $25 \pm 2.0$ & $6 \pm 0.00$ & $7 \pm 0.0$ & $3 \pm 0.9$ & $10.0 \pm 2.1$ & $7.1 \pm 2.3$ & $7.0 \pm 0.6$ & $7 \pm \pm 0.0$ \\
\hline & Mal3 & $14 \pm 1.6$ & $6 \pm 0.00$ & $7 \pm 0.0$ & $5 \pm 0.1$ & $11.2 \pm 1.8$ & $8.6 \pm 1.4$ & $8.1 \pm 1.4$ & $7 \pm \pm 0.0$ \\
\hline & Mal4 & $14 \pm 1.9$ & $6 \pm 0.00$ & $6 \pm 0.8$ & $3 \pm 1.2$ & $10.2 \pm 0.5$ & $7.1 \pm 2.9$ & $6.9 \pm 1.6$ & $7 \pm \pm 0.0$ \\
\hline & Mal5 & $13 \pm 3.1$ & $6 \pm 0.00$ & $7 \pm 0.4$ & $5 \pm 0.0$ & $9,6 \pm 0.5$ & $8.9 \pm 2.7$ & $8.5 \pm 1.1$ & $7 \pm \pm 0.0$ \\
\hline & Mal6 & $15 \pm 0.8$ & $6 \pm 0.00$ & $8 \pm 0.3$ & $4 \pm 0.1$ & $9.6 \pm 0.7$ & $8.7 \pm 0.8$ & $8.7 \pm 1$ & $7 \pm \pm 0.0$ \\
\hline & Mal7 & $14 \pm 2.4$ & $6 \pm 0.00$ & $6 \pm 0.1$ & $6 \pm 0.5$ & $10.6 \pm 0.6$ & $9.3 \pm 0.5$ & $8.9 \pm 2$ & $7 \pm \pm 0.0$ \\
\hline \multirow[t]{6}{*}{ Makthar } & Mak1 & $19 \pm 2.9$ & $6 \pm 0.00$ & $6 \pm 0.0$ & $6 \pm 0.7$ & $9.9 \pm 0.9$ & $9.0 \pm 0.6$ & $8.8 \pm 2.4$ & $7 \pm \pm 0.0$ \\
\hline & Mak2 & $21 \pm 1.3$ & $6 \pm 0.00$ & $6 \pm 0.0$ & $5 \pm 0.0$ & $11.4 \pm 2.5$ & $11.2 \pm 1.7$ & $10.8 \pm 2.3$ & $7 \pm \pm 0.0$ \\
\hline & Mak3 & $20 \pm 3.5$ & $6 \pm 0.00$ & $6 \pm 0.0$ & $5 \pm 0.2$ & $11.1 \pm 1.7$ & $10.5 \pm 2.0$ & $10.2 \pm 2.1$ & $7 \pm \pm 0.0$ \\
\hline & Mak4 & $16 \pm 1.4$ & $6 \pm 0.00$ & $6 \pm 0.0$ & $5 \pm 0.0$ & $10.7 \pm 0.8$ & $10.5 \pm 1.1$ & $10.1 \pm 1.9$ & $7 \pm \pm 0.0$ \\
\hline & Mak5 & $22 \pm 2.9$ & $6 \pm 0.00$ & $6 \pm 0.0$ & $6 \pm 1.4$ & $10.4 \pm 2.3$ & $9.8 \pm 0.9$ & $9.5 \pm 1.2$ & $7 \pm \pm 0.0$ \\
\hline & Mak6 & $18 \pm 2.2$ & $6 \pm 0.00$ & $6 \pm 0.0$ & $5 \pm 0.0$ & $10.3 \pm 1.4$ & $9.7 \pm 0.9$ & $9.5 \pm 0.8$ & $7 \pm \pm 0.0$ \\
\hline \multirow[t]{6}{*}{ Rimel } & R1 & $10 \pm 2.8$ & $5 \pm 0.00$ & $6 \pm 0.0$ & $5 \pm 0.0$ & $10.0 \pm 1.0$ & $8.9 \pm 0.5$ & $8.6 \pm 0.1$ & $8 \pm \pm 0.0$ \\
\hline & R2 & $13 \pm 1.9$ & $5 \pm 0.00$ & $6 \pm 0.0$ & $5 \pm 0.0$ & $11.8 \pm 3.7$ & $9.4 \pm 0.4$ & $9.3 \pm 0.6$ & $8 \pm \pm 0.0$ \\
\hline & $\mathbf{R 3}$ & $11 \pm 1.4$ & $5 \pm 0.00$ & $6 \pm 0.0$ & $5 \pm 0.0$ & $10.9 \pm 2.1$ & $11.5 \pm 1.5$ & $11.4 \pm 1.3$ & $8 \pm \pm 0.0$ \\
\hline & R4 & $20 \pm 2.7$ & $5 \pm 0.00$ & $6 \pm 0.0$ & $5 \pm 0.0$ & $12.5 \pm 2.8$ & $11.0 \pm 2.1$ & $10.8 \pm 1.7$ & $8 \pm \pm 0.0$ \\
\hline & R5 & $10 \pm 3.6$ & $5 \pm 0.00$ & $6 \pm 0.0$ & $5 \pm 0.0$ & $10.0 \pm 1.5$ & $10.7 \pm 1.2$ & $9.5 \pm 2.5$ & $8 \pm \pm 0.0$ \\
\hline & R6 & $12 \pm 2.2$ & $5 \pm 0.00$ & $6 \pm 0.0$ & $5 \pm 0.0$ & $10.0 \pm 0.6$ & $9.1 \pm 0.8$ & $8.5 \pm 2.0$ & $8 \pm \pm 0.0$ \\
\hline
\end{tabular}

NC : Cone number/branch, (5)/(6) : Smooth cone/rough cone, NE : Scales nuber, NG : Seeds number, H : Height, Da : Diameter a, Db :Diameter b, (7)/(8) : Proeminent tip/ not proeminent tip.

This group (G2) was characterized by the lowest number of scales ( 5 scales per cone) and the highest levels of the cone height $(10 \mathrm{~mm}<\mathrm{H}<11 \mathrm{~mm})$ and the cone diameters $(8.6 \mathrm{~mm}<$ $\mathrm{D}<11.5 \mathrm{~mm})$.

\section{Discussion and conclusion}

A morphometric analysis of 45 specimens for the branch analysis and 29 specimens for the cone analysis, of 7 and $4 \mathrm{~J}$. phoenicea populations, respectively, gathered from the northern Tunisia, showed significant taxonomic distances between two population groups. Analysis based on 5 measured parameters (quantitative parameters) and two observed parameters (qualitative parameters) of branches highlighted two population groups. A high variation within and among origins was observed for the majority of the measured treats. Established structures present no overlap between individuals of the two groups. This segregation may result from genotypic variations confirming the individualization of each morphotypes. Patterns of inherited genetic variations of morphometric traits in tree species reflect evolutionary responses to environmental races on varieties. Furthermore, we noted the emergence of a new phytogeographic structure. Indeed, populations collected from coastal sites are grouped into one group (Korbous, Laazib and Rimel) which is characterized by similar qualitative parameters (long dark branch with straightened ends and a relatively high branch number). The second group is composed by the continental populations (Makther, J. Mansour, Mallegue and Dkhila) in addition to Tabarka (coastal region with mountain features).

This group is characterized by a relatively shorter and light colored twigs, leaning branches and lower ramification number. Likewise, the polymorphism analysis of J. phoenicea cones based on six measured parameters and two observed parameters showed the existence of two different geographical structures. The first group is formed by three continental populations (Makther, Mallegue and J. Mansour). Specimens are characterized by similar qualitative parameters (rough appearance with prominent tips) and by a relatively moderate length, height and diameter measurements. 
Table 6 Correlations coefficients between \& considered characters of $J$. phoenicea cones from all populations sampled.

\begin{tabular}{|c|c|c|c|c|c|c|c|c|}
\hline & $\mathrm{NC}$ & $(5) /(6)$ & NE & NG & $\mathbf{H}$ & $\mathbf{D a}$ & Db & $(7) /(8)$ \\
\hline $\mathrm{NC}$ & 1.0 & & & & & & & \\
\hline$(5) /(6)$ & 0.16 & 1.0 & & & & & & \\
\hline NE & 0.05 & 0.11 & 1.0 & & & & & \\
\hline NG & -0.08 & -0.12 & -0.06 & 1.0 & & & & \\
\hline H & 0.16 & -0.13 & 0.05 & 0.23 & 1.0 & & & \\
\hline Da & 0.00 & -0.25 & -0.13 & 0.43 & 0.6 & 1.0 & & \\
\hline Db & 0.08 & 0.02 & -0.02 & 0.02 & 0.08 & 0.09 & 1.0 & \\
\hline$(7) /(8)$ & -0.1 & -0.86 & -0.13 & 0.05 & 0.19 & 0.23 & -0.01 & 1.0 \\
\hline
\end{tabular}

The second group is formed by one coastal region (Rimel). Specimens are characterized by smooth cones, non prominent peaks and the highest averages of height and diameter measurements. Moreover, variability within the same group and between individuals of different populations was observed. This could be the result of an overlap of specimens of different populations which are characterized by similar morphological characteristics.

Our study on the genetic variation in Tunisian J. phoenicea gives information to guide conservation strategy. The used morphological treats allowed a high differentiation among coastal and continental populations indicating a low level of gene flow among them due probably to a low hybridization level, geographical isolation and limited seed exchange. Within geographical regions, the highest level of variation was observed within and among continental sites (J. Mansour, Makther, Dkhila and Mallegue) and the lowest within the coastal ones (Laazib, Rimel and Korbous). Thus, the conservation in-situ and ex-situ allowing the maintenance of interaction between populations should be considered.

However, according to these results, we can't exclude the hypothesis of the existence of two morphotypes differentiated by their morphological features and occupying two different geographical territories. Thus, based on the Grandoger collects in 1907 near to Hammamet and Nabeul (coastal regions) and Van Slageren collects in Matmata, Farajon, (2005) in his book "Monograph of Cupressaceae and Sciadopitis" reported the presence of two taxa belonging to the species of J. phoenicea: $J$. phoenicea ssp. phoenicea in Matmata and J. phoenicea ssp. turbinata (Guss.) Pal. in Hammamet. We conclude the existence of two subspecies of $J$. phoenicea. The first one $J$. phoenicea ssp. turbinata, located in the coastal sites, is characterized by long, dark and drawn branches and relatively bulky cones. The second one, J. phoenicea ssp. phoenicea occupied the continental regions in the western side of Tunisia, is characterized by a short leaning and light colored branches and a rough appearance cones with a prominent tips. This new finding allows the update of the flora of Tunisia already realized by Pottier Alapetite \& Labbe, (1954) who didn't mentioned the existence of these two subspecies.

Our findings are in agreement with what was reported by Mazur et al., 2015, who on the basis of the morphometric analysis of six $J$. phoenicea populations from the Mediterranean region showed the existence of two $J$. phoenicea subspecies: $J$. phoenicea ssp. phoenicea and $J$. phoenicea ssp. turbinata. The latter, has a restricted west Mediterranean distribution. In particular, it is present on the mountains and hills of Spain, France and also Italy in west Liguria, also in Tuscany on the Apuane Alps (Arrigoni, 2012). While $J$. phoenicea ssp. turbinata is more abundant in southern Sicily coasts (Mazur et al., 2015).

These results confirm the genetic differentiation of the taxons (Lewandovski et al., 2000) and also the biochemical and morphological division of them (Lebreton \& Thievend, 1981; Lebreton \& Thievend, 1989). Nevertheless, the distances between each population are so great that they more resemble the distances between species than subspecies (Mazur et al., 2003).

It is noteworthy that the two species do not interbreed even when they are in close proximity. In fact $J$. phoenicea ssp. phoenicea sheds pollen in the spring and $J$. phoenicea ssp turbinata in the autumn (Mazur et al., 2015). Indeed, such hypothesis should be confirmed by a molecular markers study to deepen the assessment of the genetic variation and to suggest appropriate conservation strategy.

\section{Conflict of interest}

Authors would hereby like to declare that there is no conflict of interests that could possibly arise.

\section{References}

Anderson B, Johson SD (2008) The geographical conservation mosaic of coevolution in a plant-pollinator mutualism. Evolution 62:220-225.

Arrigoni PV (2012) Miscellaneous notes about some taxa of the Italian flora. Webbia $67: 37-46$.

Schulz C, Jagel A, Stutzel T (2003) Cone morphology in Juniperus in the light of cone evolution in Cupressaceae s.l. Flora 198: 161-177.

Futuyma DJ (1998) evolutionary biology. Sinauer Associates, Massachussets. 
Gould SJ, Jhonso RF (1972) Geographic variation. Annual review of ecology and systematic 3: 115-151.

Guetet A, Zammouri J, Boussaid M, Neffati M (2009) The use of reproductive vigor descriptors to study genetic variability in wild populations of Allium roseum (Alliaceae) in Tunisia. Scientia Horticulturae 120: 282-287.

Herrara CM, Castellanos MC, Medrano M (2006) Geographical context of floral evolution: towards an improved research program in floral diversification. Oxford University press, oxford pp. 278-294.

James SC, Corney D, Jonathan Y.C, Remagnino P, Wilkin P (2012) Plant species identification using digital morphometrics. Expert systems with applications 39: 75627573.

Julieta N, Alicia NS, Andrea AC (2011) Geographic variation of floral traits in Nicotiana glauca: relationships with biotic and abiotic factors. Acta Oecologica 37: 503-511.

Keskes H, Mnafgui K, Hamden K, Damek M, El feki A, Allouche N (2014) In vitro anti-diabetic, anti-obesity and antioxidant properties of Juniperus phoenicea L. leaves from Tunisia. Asian Pacific Journal of Tropical Biomedicine 4: 649655.

Klimko M, Boratynska K, Monteserrat J.M, Didukh Y, Romo A, Gomez D, Kluza-Wieloch M, Marcysiak K, Boratynska A (2007) Morphological variation of Juniperus oxycedrus subsp. Oxycedrus (Cupressaceae) in the mediterranean rgion. Flora $202: 133-147$

Lebreton P, Thievend S (1981) Sur une sous-espece du genevrier de Phenicie L. definie a partir de criteres biochimiques. Naturalia monspeliensia Ser Botany 47:1-12.

Lebreton P, Thievend S (1989) Analyse du taxon Juniperus phoenicea L. sur des bases biochimiques et biometriques. Naturalia monospeliensia Ser Botany 53:17-41.

Lewandowski A, Boratynski A, Mejnartowicz L (2000) allozyme investigations on the differenciation between closely related pines-Pinus sylvestris L. P. mugo Turra, P. uncinata Ramond ex DC and P. ulginosa Neumann (Pinaceae). Plant system evolution 221: 15-24.

Mazur M, Minissale P, Sciandrello S, Boratynsky A (2015) Morphological and ecological comparision of populations of Juniperus Turbinata Guss. And Juniperus phoenicea L. from the Mediterranean region. Plant Biosystems 1-10.

Mazur M, Boratynska K, Marcysiac K, Gomez D, Tomazewski D, Didukh J, Boratynski A (2003) Morphological variability of Juniperus phoenicea (Cupressaceae) from three distant localities on Iberian Peninsula. Acta societatis botanicorum Poloniae 72: 71-78.

Medini H, El Aissi A, Farhat F, Khouja ML, Chemli R, Harzallah-Skhiri F (2009) Seasonal and geographical influences on the chemical composition of Juniperus phoenicea L. essential oil leaves from the Northern Tunisia. Chemistry and Biodiversity 6: 1378-1387.

Medini H, Elaissi A, Khouja ML, Chemli R (2013a) Phytochemical screening and antioxidant activity of Juniperus phoenicea ssp. phoenicea L. extracts from two Tunisian localities. Journal of Experimental Biology and Agricultural Sciences $1: 77-82$.

Medini H, Elaissi A, Marongiu B, Falconieri D, Piras A, Porcedda S, Khouja ML, Chemli R, Harzallah-Skhiri F (2013b) Antibacterial and phytochemical composition of leaf and berry essential oils of two Juniperus phoenicea subspecies gathered in Tunisa. Journal of Experimental Biology and Agricultural Sciences $1: 166-173$.

Perez-Barrales R, Pini R, Albaladejo RG, Arroyo J (2009) Geographic variation of flower traits in Narcissus papyraceus (Amaryllidaceae): do pollinators matter?. Journal of Biogeography 36: 1411-1422.

Pottier-Alapetite G, Labbe A (1954) Flore Analytique et Synoptique de la Tunisie. Tome I 27.

Quezel P, Barrero M (1980) Biogeographie et ecologie des conifers sur le pourtour Mediterraneen. Actualites d'ecologie forestiere. Gauthier-Villars, Paris 205-255.

Quezel P, Barrero M (1981) Contribution a l'étude des formations pré-steppiques a Genévrier au Maroc. Boletim da sociedad Broteriana 53 : 1137-1160.

Quezel P, Barrero M, Benabid A, Rivas Marinez S (1992) Contribution a l'étude des groupements forestiers et préforestiers du Maroc oriental. Stidia botany 10 : 57-90.

Rojas M (1992) The species problem and conservation: what are we protecting?. Biology conservation 3:206-208.

Scott JM, Murray M, Wright RG, Csuti B, Morgan P, Pressey RL (2001) Representation of natural vegetation in protected areas: capturing the geographic range. Biodiversity Conservation 10: 1297-1301.

Sutherland WJ (2000) the conservation handbook. Research management and policy. Blackwell, oxford.

Thompson JN (1994) The coevolutionary process. The university of Chicago press, Chicago. 